\title{
Abnormal correlation of circulating endothelial progenitor cells and endothelin-1 concentration may contribute to the development of arterial hypertension in childhood acute lymphoblastic leukemia survivors
}

\author{
Tomasz Ociepa ${ }^{1}$, Magdalena Bartnik ${ }^{1}$, Karolina Zielezinska ${ }^{1}$, Mai Prokowska ${ }^{2}$, Elzbieta Urasinska ${ }^{2}$ and \\ Tomasz Urasinski ${ }^{1}$
}

It is well known that the rate of arterial hypertension (AH) in childhood acute lymphoblastic leukemia (ALL) survivors is significantly higher than that in the healthy pediatric population; however, the mechanism of this phenomenon is not fully understood. The developing cardiovascular system in children is thought to be highly susceptible to the toxic effects of chemotherapy, which causes damage to the blood vessel wall, including the endothelium. Endothelin-1 (ET-1) is a marker of endothelial damage, and it contributes to AH. Endothelial progenitor cells (EPCS) are derived from the bone marrow and participate in the process of blood vessel repair. The aim of this study was to determine the relationship between the rate of circulating EPCs and plasma levels of ET-1 with respect to hypertension in childhood ALL survivors. The study included 88 childhood ALL survivors and 44 healthy children as controls. All patients and controls had 24 -h blood pressure monitoring with a HoICARD CR-07 device. The number of EPCs and the ET-1 serum concentration were measured in the peripheral blood of patients and controls using flow cytometry and enzyme-linked immunosorbent assay, respectively. A correlation was found between the number of EPCs and the ET-1 concentration in the peripheral blood of healthy children and normotensive ALL survivors. However, such a correlation was not found in hypertensive childhood ALL survivors. We conclude that dysregulation of the 'ET-1 and EPC axis' may contribute to the development of AH in some childhood ALL survivors.

Hypertension Research (2016) 39, 530-535; doi:10.1038/hr.2016.22; published online 3 March 2016

Keywords: acute lymphoblastic leukemia; arterial hypertension; children; endothelin-1; endothelial progenitor cells

\section{INTRODUCTION}

The introduction of intensive chemotherapy, better methods of risk assessment and supportive care led to improvement in the long-term survival rate in children with acute lymphoblastic leukemia (ALL). Now, over $85 \%$ of all children with ALL can be successfully treated. ${ }^{1-3}$ However, the increased number of childhood ALL survivors is associated with an increased prevalence of cardiovascular disease including hypertension, which is found to be a major cause of non-cancer morbidity and mortality in this group of patients. ${ }^{4-10}$

The pathomechanism of hypertension in childhood leukemia survivors is not fully understood. The developing cardiovascular system in children is thought to be highly susceptible to the toxic effects of chemotherapeutic agents. ${ }^{7,11}$ Administration of various cytostatic agents may directly or indirectly cause endothelial damage. ${ }^{6,12,13}$ Endothelin-1 (ET-1) is a peptide produced by the endothelium that mainly has a role as a vasoconstrictor. ET-1 is considered a potential marker of endothelial injury and dysfunction. ${ }^{13,14}$ Furthermore, ET-1 may contribute to the development of hypertension, atherosclerosis and coronary artery disease. ${ }^{15,16}$

Endothelial progenitor cells (EPCs) are derived from the bone marrow and contribute to the repair of vessel injury through differentiation into endothelium. The results of several studies indicate that EPCs are positive for (express) CD34, CD133 and CD309 surface antigens. ${ }^{17-20}$

Although the role of circulating EPCs has still not been fully elucidated, it is believed that their decreased number or abnormal function may hasten cardiovascular disease, including hypertension. Moreover, Werner et al. ${ }^{17}$ showed that an increased level of EPCs was associated with a reduced risk of death from cardiovascular causes. At least two published reports confirm the positive effect of intracoronary injection of EPCs in patients with acute myocardial infarction. ${ }^{21,22}$

${ }^{1}$ Department of Pediatrics, Hematology and Oncology, Pomeranian Medical University, Szczecin, Poland and ${ }^{2}$ Department of Pathology, Pomeranian Medical University, Szczecin, Poland

Correspondence: Dr T Ociepa, Department of Pediatrics, Hematology and Oncology, Pomeranian Medical University, ul. Unii Lubelskiej 1, Szczecin 71-252, Poland.

E-mail: tociepa@sci.pum.edu.pl or tociepa@gmail.com

Received 15 June 2015; revised 17 December 2015; accepted 25 January 2016; published online 3 March 2016 
We hypothesize that the development of arterial hypertension $(\mathrm{AH})$ in some cohorts of children treated for ALL result from an impaired balance between excessive endothelial injury and decreased (insufficient) repair. Thus, we aimed to measure and analyze the rate and number of EPCs and the levels of plasma ET-1 in children with ALL and in the control group. Our second aim was to investigate the relationships between EPCs, ET-1 and the development of hypertension in children with ALL.

\section{PATIENTS AND METHODS}

\section{Study design}

All patients with a history of ALL who were treated in the Department of Pediatrics, Hematology and Oncology (Pomeranian Medical University, Szczecin, Poland) between January 1999 and December 2012 were invited to participate in the study. Those patients who responded to the invitation for participation were included in the study.

The study was approved by the Bioethical Committee of Pomeranian Medical University in Szczecin, Poland (approval no. KB-0012/69/12).

\section{Patients and controls}

Between January 1999 and December 2012, 168 patients received intensive chemotherapy for ALL at our institution. The study group included 88 patients who survived in first remission and accepted the invitation.

The control group (control) consisted of 44 healthy children with no evidence of hypertension.

Informed consent was obtained from all parents and all children with the exception of those younger than 6 years of age.

\section{Definition and diagnosis of $\mathrm{AH}$}

Blood pressure assessments were performed with the use of the standard oscillometric 24-h ambulatory blood pressure monitoring device (HolCARD CR-07; Aspel S.A., Zabierzow, Poland). Measurements were taken every 20 min during the daytime and every $30 \mathrm{~min}$ during the nighttime. The accuracy and reproducibility of the method for measuring 24 -h blood pressure were checked by simultaneous measurements with an automated oscillometric upper arm blood pressure monitor (Omron M7, HEM-780-E, Omron Healthcare Corporation, Kyoto, Japan) at the beginning and at the end of the test period. Blood pressure values were recorded as systolic, diastolic and mean arterial blood pressure. $\mathrm{AH}$ was defined as either systolic and/or diastolic pressure above or equal to the 95th percentile for age, height and sex during any recorded period (24-h, daytime or nighttime).

\section{Flow cytometry (assessment of circulating EPCs)}

Before processing the blood samples, the WBC count for each patient was calculated using a hematology analyzer. Aliquots of $0.5 \mathrm{ml}$ of sampled blood were placed in two plastic tubes and incubated for $20 \mathrm{~min}$ at room temperature in darkness with monoclonal antibodies. The first tube contained anti-IgG1 APC (allophycocyanin) (BD Bioscience, San Jose, CA, USA; cat. no. 345818), anti-IgG2b PE (phycoerythrin) (BD Pharmingen, San Jose, CA, USA; cat. No. 556656), anti-CD34 FITC (fluorescein isothiocyanate) (BD Bioscience; cat. no. 345801) and anti-CD45 PerCP (peridinin chlorophyll protein complex) (BD Bioscience; cat. no. 345809); the second tube contained anti-CD34 FITC (BD Bioscience; cat. no. 345801), anti-CD45 PerCP (BD Bioscience; cat. no. 345809), anti-CD133 PE (Miltenyi Biotec; cat. no. 130-090-863) and antiCD309 APC (Miltenyi Biotec, Bergisch Gladbach, Germany; cat. no. 120-006197). Monoclonal antibodies anti-IgG1 PE and anti-IgG2b were used as negative controls to distinguish specific from nonspecific binding to human cells, whereas the remaining antibodies, anti-CD34, anti-CD45, anti-CD133 and anti-CD309, were used to measure and calculate the rate and number of EPCs. After incubation, red cells were lysed using BD FACS Lysing Solution (Becton Dickinson; cat. no. 349202) and diluted with distilled water (1:10). After $10 \mathrm{~min}$ of incubation, the cells were centrifuged for $10 \mathrm{~min}$ at 550 r.p.m., washed with BD CellWash (Becton Dickinson; cat. no. 349524) and centrifuged again for $10 \mathrm{~min}$ at 550 r.p.m. Then, the cell pellets were resuspended in $0.5 \mathrm{ml}$ of BD FACSFlow (Becton Dickinson; cat. no. 342003). Measurements of fluorescence intensity were performed using a BD FACSCanto II flow cytometer supplied with three lasers: violet $(405 \mathrm{~nm})$, blue $(488 \mathrm{~nm})$ and red $(633 \mathrm{~nm})$. The principles of the measurements of EPCs are shown in Figure 1. In brief, mononuclear cells were gated on the basis of forward scatter (FSC-A) vs. side scatter (SSC-A) (dot plot A). Cells collected from region 1 were subjected to CD45 vs. SSC-A analysis (dot plot B) to eliminate CD45 - cells. Cells from region 2 were then displayed on CD34 vs. SSC-A (dot plot C) to select CD34 +/CD45+ cells. Finally, CD34+/CD45+ cells from region 3 were analyzed with respect to $\mathrm{CD} 309$ and $\mathrm{CD} 133$ expression (dot plot D). The results were expressed as the percentage of CD133+/CD309+/CD34+ cells and the absolute number of $\mathrm{CD} 133+/ \mathrm{CD} 309+/ \mathrm{CD} 34+$ cells calculated as the percentage of CD133+/CD309+/CD34+ cells $\times$ WBCs (cells per microliter).

\section{ET-1 concentration measurements}

The Quantikine Endothelin-1 immunoassay (sandwich enzyme-linked immunosorbent assay) for serum ET-1 concentrations was used in accordance with the manufacturer's instructions (R\&D System, Minneapolis, MN, USA). Blood samples were obtained from a peripheral vein in all patients and controls. Blood was collected in tubes without any anticoagulant and subsequently centrifuged $\left(15 \mathrm{~min}\right.$ at $1000 \mathrm{~g}$ ). The serum was stored at $-80^{\circ} \mathrm{C}$ until ET-1 assessment.

\section{Statistical analysis}

Data were expressed as the mean \pm s.d. Continuous variables between groups (number of circulating EPCs, ET-1 concentrations, age, age of diagnosis, time of follow-up and body mass index values) were compared by the two-tailed Mann-Whitney test. Correlations were made using the two-tailed Spearman rank test. $P$ values of $\leqslant 0.05$ were considered significant. All statistical analyses were performed using the 'Statistica' (StatSoft, Inc., Tulsa, OK, USA, ver. 10) software.

\section{RESULTS}

\section{Patients' characteristics}

Patients with ALL were divided into two groups: (i) with AH (hypertensive ALL; $n=33$ ) and (ii) without AH (normotensive ALL; $n=55)$. In total, $37.5 \%(33 / 88)$ of patients from the cohort of ALL patients met the criteria for $\mathrm{AH}$. The characteristics of the patients and controls are shown in Table 1.

\section{Levels of ET-1 and number of EPCs}

The mean values of EPCs and ET-1 concentrations in all of the groups studied are presented in Table 2. No significant difference was found between the levels of EPCs and ET-1 in hypertensive ALL patients, normotensive ALL patients and controls. The rates of circulating EPCs were lowest in hypertensive ALL children, but did not differ significantly from normotensive ALL patients and the control group $(0.0018 \pm 0.0026$ vs. $0.0031 \pm 0.0042$ vs. $0.0031 \pm 0.0047$, respectively; $P>0.05$ ).

There were no significant correlations between patient's age, age at diagnosis of ALL, body mass index and rates of EPCs and levels of ET-1 in all of the groups studied.

There was a positive correlation between levels of ET-1 and the time of follow-up in the hypertensive ALL group $(r=0.34 ; P=0.04)$ (Figure 2a), but not in the normotensive ALL group. There was an inverse correlation between levels of EPCs and the time of follow-up in the hypertensive ALL group $(r=-0.36 ; P=0.038$ ) (Figure $2 \mathrm{~b}$ ), but not in the normotensive ALL group. There was no difference in follow-up time between hypertensive and normotensive ALL patents.

\section{Correlation between circulating EPCs and levels of ET-1}

Circulating EPCs correlated with serum ET-1 levels in normotensive ALL patients and in controls $(r=0.44, P=0.0008$ and $r=0.588$, $P=0.00003$, respectively) (Figures $3 \mathrm{a}$ and $\mathrm{b}$ ). However, there was no 
a

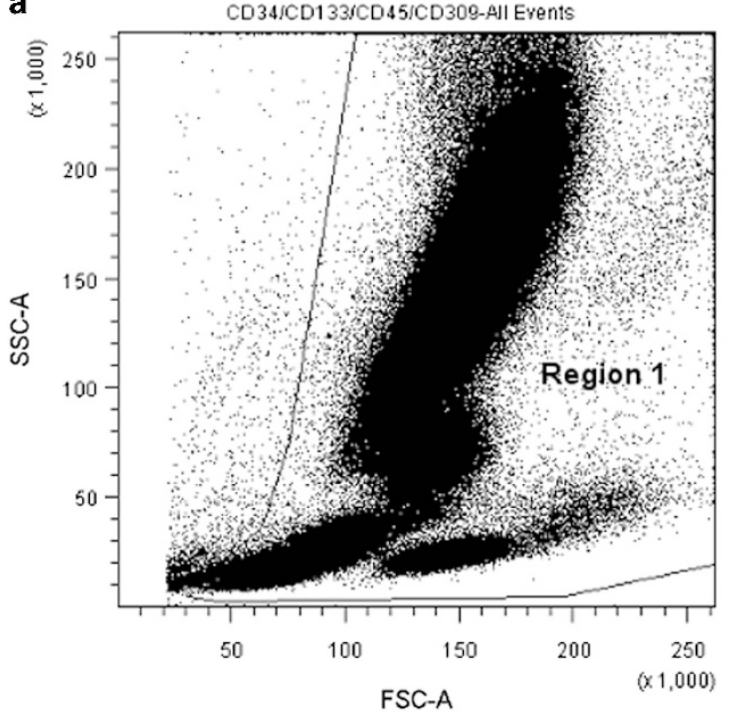

d

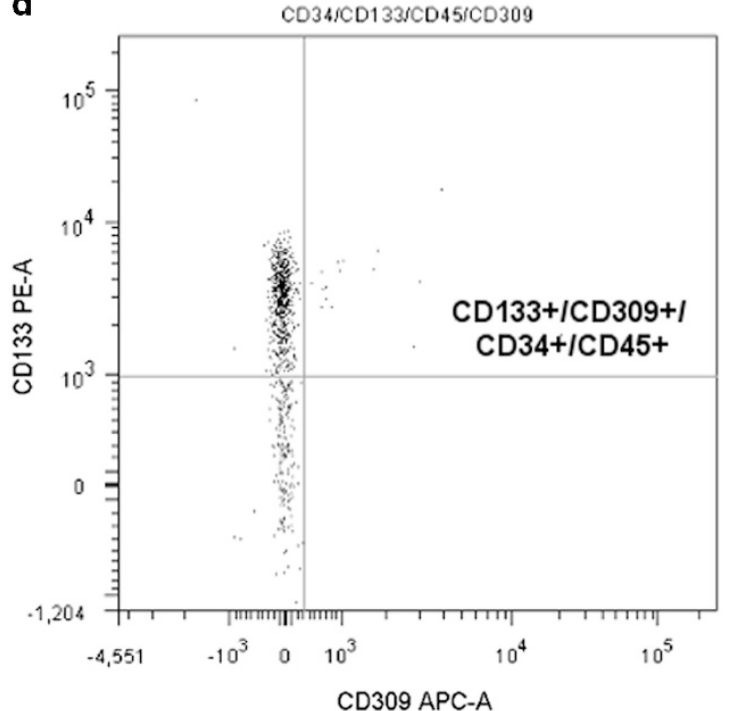

b

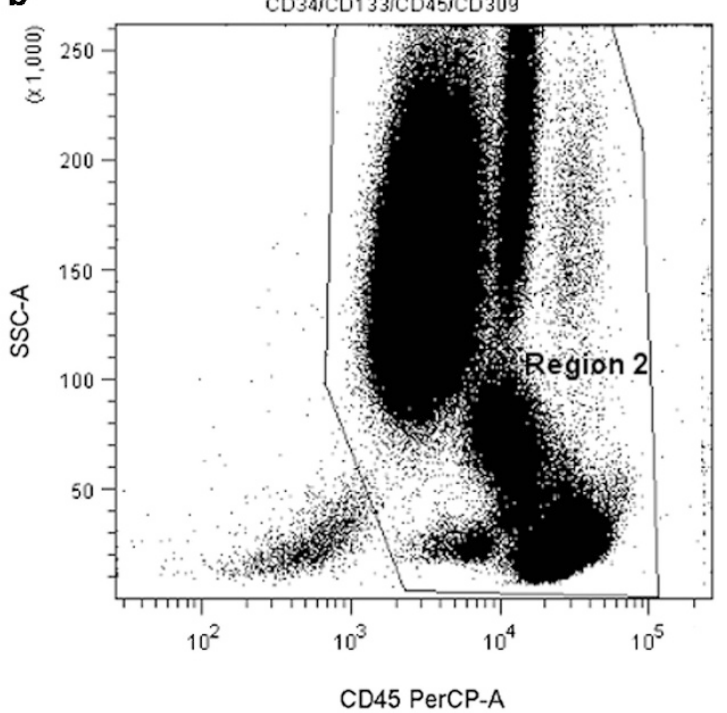

C

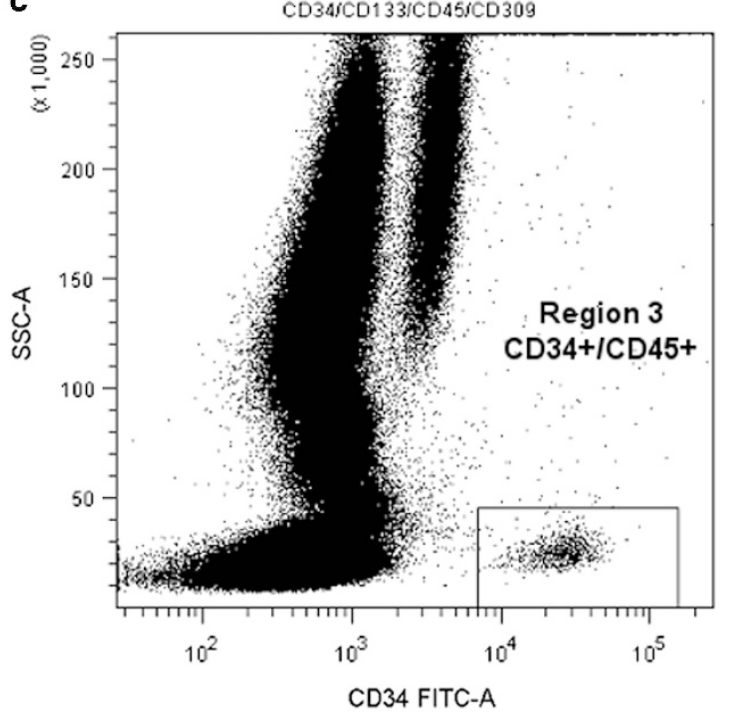

Figure 1 Principles of measurement of the rates of CD133+/CD309+/CD34+/CD45+ endothelial progenitor cells (EPCs). Mononuclear cells were gated on the basis of forward scatter (FSC-A) vs. side scatter (SSC-A) (dot plot (a)). Cells collected from region 1 were subjected to CD45 vs. SSC-A analysis (dot plot (b)). Cells from region 2 were then displayed on CD34 vs. SSC-A (dot plot (c)) to select CD34+/CD45+ cells. Finally, CD34+/CD45+ cells from region 3 were analyzed with respect to CD309 and CD133 expression (dot plot (d)).

correlation between circulating EPCs and serum ET-1 levels in hypertensive ALL patients $(r=-0.117 ; P=0.51$ ) (Figure 3c).

\section{DISCUSSION}

AH affects ALL survivors more often than healthy children. According to the Childhood Cancer Survivors Study, performed by Meacham et al. ${ }^{23} \mathrm{AH}$ occurs in approximately $9 \%$ of cancer survivors. This figure seems to be underestimated. Contrary to the Meacham report, in our study, AH was detected in $37.5 \%$ of ALL survivors. This discrepancy may be explained by the fact that our analysis was restricted to ALL survivors only. Esbenshade et al. ${ }^{24}$ reported that $41.5 \%$ of ALL children undergoing treatment fulfilled the criteria for systolic and/or diastolic hypertension.

Most of the published studies on $\mathrm{AH}$ in children with leukemia define $\mathrm{AH}$ on the basis of casual oscillometric measurements. ${ }^{4,25}$
However, 24-h ambulatory blood pressure monitoring has become the gold standard for AH diagnosis in children as well as in adults. ${ }^{26,27}$

Proposed risk factors for $\mathrm{AH}$ development include drugs (glucocorticoids, methotrexate and anthracyclines), cranial irradiation, obesity and metabolic syndrome. ${ }^{6,23,24}$ Limited data and contradicting results make the associations between these risk factors and subsequent $\mathrm{AH}$ development in children with leukemia unclear. ${ }^{5}$

The higher incidence of AH in ALL survivors than in the general population may indicate that some additional risk factors might contribute to $\mathrm{AH}$ development in this group of patients.

Endothelial dysfunction caused by chemotherapy is a possible and attractive hypothesis. It has been shown that the administration of methotrexate, one of the most commonly used anti-leukemic agents, is associated with the elevation of plasma homocysteine. ${ }^{12}$ It is believed that hyperhomocysteinemia leads to subsequent endothelial injury and endothelial dysfunction. ${ }^{6,14}$ The endothelium is an important 
Table 1 Patients and control characteristics

\begin{tabular}{|c|c|c|c|c|c|}
\hline Characteristics & Hypertensive ALL $(\mathrm{n}=33)$ & Normotensive ALL $(n=55)$ & P-value & Control $(n=43)$ & P-value2 \\
\hline Age, years (mean \pm s.d./median) & $9.91 \pm 4.84 / 9$ & $12.2 \pm 5.09 / 13$ & 0.029 & $11.73 \pm 4.27 / 12$ & $0.08 / 0.59$ \\
\hline Age at ALL diagnosis, years (mean \pm s.d./median) & $5.21 \pm 3.84 / 4$ & $6.73 \pm 4.63 / 5$ & NS & na & na \\
\hline Obesity: BMI > 95 centile (\%) & $7 / 33(21)$ & $4 / 55(7.2)$ & 0.09 & & \\
\hline Z-score BMI (mean \pm s.d.) & $0.73 \pm 1.137$ & $0.12 \pm 1.038$ & 0.011 & $-0.27 \pm 1.345$ & $0.0009 / 0.1$ \\
\hline Sex female $(\%)$ & $16(48)$ & $22(40)$ & 0.5 & $18(42)$ & $1 / 0.64$ \\
\hline IR (\%) & $19(57.6)$ & $35(63.6)$ & NS & na & na \\
\hline HR (\%) & $2(6)$ & $4(7.2)$ & NS & na & na \\
\hline RTX (+) (\%) & $5(15)$ & $15(27.3)$ & NS & na & na \\
\hline
\end{tabular}

Abbreviations: BCP, B-cell precursor; BMI, body mass index; HR, high risk; IR, intermediate risk; na, not applicable; NS, not significant; RTX (+), cranial radiotherapy; SR, standard risk; $P$ value, hypertensive ALL vs. normotensive ALL; P value2, hypertensive ALL vs. control/normotensive ALL vs. control.

Table 2 The mean values of EPCs and ET-1 concentrations in the groups studied and in the controls

\begin{tabular}{lcccc}
\hline Characteristic & Hypertensive ALL $(\mathrm{n}=33)$ & Normotensive ALL $(\mathrm{n}=55)$ & P-value & Control $(\mathrm{n}=43)$ \\
\hline EPCs per $\mathrm{ml}($ mean \pm s.d.) & $92.12 \pm 113.1$ & $120.78 \pm 145.08$ & $\mathrm{NS}$ & $146.44 \pm 212.33$ \\
\%EPCs $\left(\mathrm{mean}_{ \pm}\right.$s.d.) & $0.0018 \pm 0.0026$ & $0.0031 \pm 0.0042$ & $\mathrm{NS}$ & $0.0031 \pm 0.0047$ \\
ET-1 $\left(\mathrm{pg} \mathrm{ml}\right.$ (mean $^{-1}$ s.d.) & $1.97 \pm 0.85$ & $2.1 \pm 0.7$ & $\mathrm{NS}$ & $2.013 \pm 1.17$ \\
\hline
\end{tabular}

Abbreviations: EPCs, endothelial progenitor cells; ET-1, serum endothelin-1; NS, not significant; $P$ value, hypertensive ALL vs. normotensive ALL; $P$ value2, hypertensive ALL vs. control/normotensive ALL vs. control.

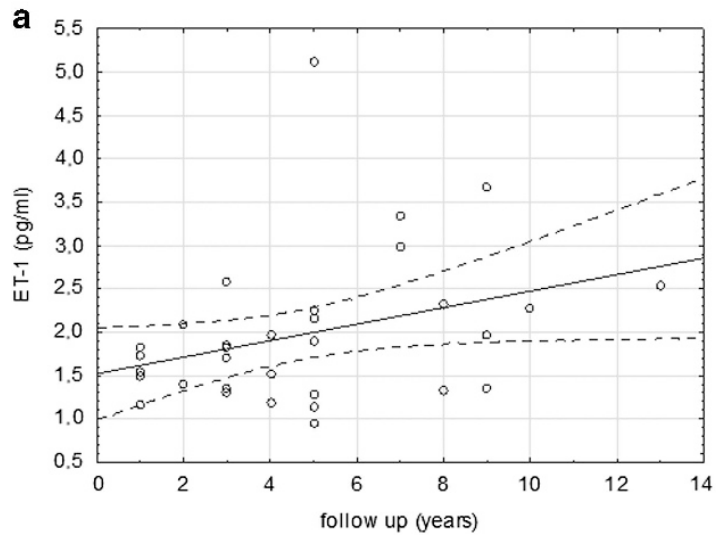

Figure 2 The correlations between levels of ET-1 (a), rates of circulating EPCs (b) and time of follow-up in hypertensive ALL patients.

regulator of vascular tone. Its dysfunction, leading to impaired vasodilation, inflammation and enhanced thrombotic activity, has an important role in the development of atherosclerosis, hypertension and cardiovascular disease including coronary artery disease. ${ }^{14,28}$

Several studies have highlighted the role of ET-1 in atherosclerosis and the development of AH. ET-1, a peptide produced by the endothelium of blood vessels in response to endothelial damage, has high vasoconstrictor potency and has been considered a marker of endothelial dysfunction. ${ }^{14,15,29,30}$ Increased levels of ET-1 were found in patients with hyperlipidemia, diabetes, heart failure, atherosclerosis, chronic kidney disease and pheochromocytoma. Increased levels of ET-1 were also found in subjects with risk factors for atherosclerosis such as cigarette smoking. ${ }^{14,15,28,31}$ It should also be noted that Akter et al. $^{32}$ found elevated levels of ET-1 in hypertensive subjects.

In our study, ET-1 levels did not differ significantly between the study group and controls. However, we found a positive correlation b

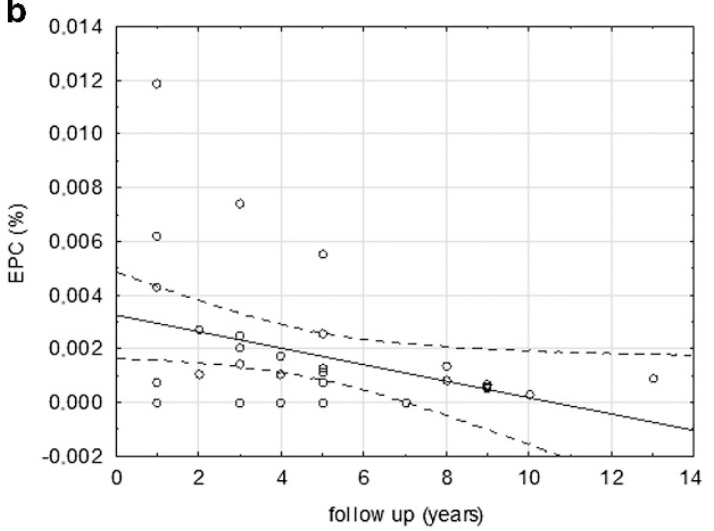

between ET-1 levels and the time of follow-up exclusively in hypertensive, but not normotensive, ALL patients. We speculate that this phenomenon may reflect the progression of vascular injury in hypertensive children with ALL.

Under normal conditions, endothelial injury is counterbalanced by endothelial repair. EPCs contribute to the restoration of epithelium integrity. They are derived from the bone marrow, and circulate in the blood, with the ability to differentiate into endothelial cells. ${ }^{33}$ It is believed that EPCs are inversely correlated with endothelial dysfunction and cardiovascular disease outcome in humans. ${ }^{17,34,35}$

In our hypertensive ALL cohort, the number of circulating EPCs was lower than that detected in the remaining groups, although these differences were not statistically significant. This observation may be evidence that chemotherapeutic agents are responsible not only for epithelial damage but also for the decreased rate of bone marrow production of EPCs. 

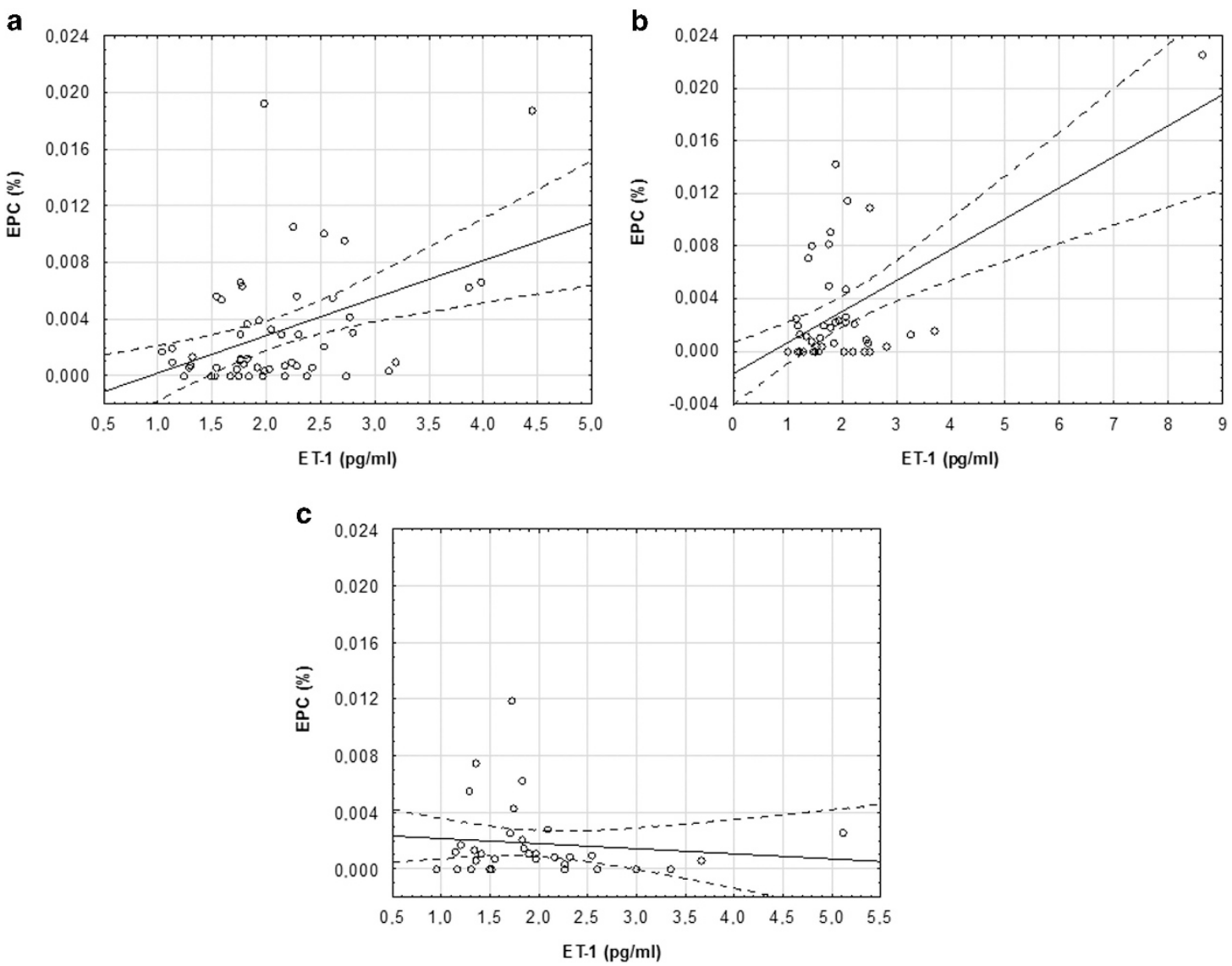

Figure 3 The correlations between circulating EPCs and serum ET-1 levels in the normotensive ALL group (a), the controls (b) and the hypertensive ALL cohort (c).

An inverse correlation between circulating EPCs and time of follow-up was exclusively seen in the hypertensive ALL group. This correlation was not found in normotensive ALL patients or in controls.

In vitro data have not confirmed any direct effect of ET-1 on EPC function. However, it has been assumed that an indirect association between ET-1 and EPCs does exist at least in different clinical settings. ${ }^{36,37}$ Paczkowska et al. ${ }^{18}$ reported enhanced EPC mobilization by ET-1 in patients with ischemic stroke. Furthermore, this study also indicated the role of ET-1 in EPC recruitment into damaged neural tissue.

In our study, we found a positive correlation between circulating EPCs and serum ET-1 levels in normotensive ALL patients and in controls, but not in hypertensive patients. Considering that the ET-1 concentration reflects the level of endothelial damage, whereas the number of EPCs indicates the ability for endothelial restoration, we speculate that, in normotensive ALL patients and controls, there is a balance between endothelial damage, represented by ET-1, and endothelial regeneration, reflected by EPCs. If this is true, it would indicate the existence of an 'ET-1/EPC axis' and the role of disturbed relations between ET-1 and EPCs in the development of AH in some ALL survivors. We hypothesize that, in normotensive ALL survivors and controls, ET-1 might mobilize EPCs for endothelial repair and regulate vascular tone in response to endothelial injury. We suspect that, in some ALL survivors, this 'axis' is malfunctioning, thus resulting in the development of AH. A lack of either EPC expansion, mobilization or intravascular activity in some ALL survivors may correspond with an impaired subsequent response to ET-1, which is per se one of the signs of endothelial damage.

Our results may also suggest that hypertension in childhood ALL survivors should be treated with angiotensin II receptor antagonists as it has been shown by Yoo et al. ${ }^{38}$ in an experimental model that telmisartan may increase the number of EPCs in hypertensive rats.

We conclude that significant endothelial damage and the concomitant decreased ability of EPCs to repair the endothelium may contribute to the development of $\mathrm{AH}$ in a significant number of childhood ALL survivors. Further studies are needed to confirm this hypothesis.

\section{CONFLICT OF INTEREST}

The authors declare no conflict of interest.

1 Vora A, Goulden N, Wade R, Mitchell C, Hancock J, Hough R, Rowntree C, Richards S. Treatment reduction for children and young adults with low-risk acute lymphoblastic leukaemia defined by minimal residual disease (UKALL 2003): a randomised controlled trial. Lancet Oncol 2013; 14: 199-209.

2 Pui CH, Pei D, Campana D, Cheng C, Sandlund JT, Bowman WP, Hudson MM, Ribeiro RC, Raimondi SC, Jeha S, Howard SC, Bhojwani D, Inaba H, Rubnitz JE, Metzger ML, Gruber TA, Coustan-Smith E, Downing JR, Leung WH, Relling MV, Evans WE. A revised definition for cure of childhood acute lymphoblastic leukemia. Leukemia 2014; 28: 2336-2343.

3 Pui CH, Campana D, Pei D, Bowman WP, Sandlund JT, Kaste SC, Ribeiro RC, Rubnitz JE, Raimondi SC, Onciu M, Coustan-Smith E, Kun LE, Jeha S, Cheng C, Howard SC, Simmons V, Bayles A, Metzger ML, Boyett JM, Leung W, Handgretinger R, Downing JR, Evans WE, Relling MV. Treating childhood acute lymphoblastic leukemia without cranial irradiation. N Engl J Med 2009; 360: 2730-2741. 
4 Chow EJ, Pihoker C, Hunt K, Wilkinson K, Friedman DL. Obesity and hypertension among children after treatment for acute lymphoblastic leukemia. Cancer 2007; 110 2313-2320.

5 Veringa SJ, van Dulmen-den Broeder E, Kaspers GJ, Veening MA. Blood pressure and body composition in long-term survivors of childhood acute lymphoblastic leukemia. Pediatr Blood Cancer 2012; 58: 278-282.

6 Oeffinger KC. Are survivors of acute lymphoblastic leukemia (ALL) at increased risk of cardiovascular disease? Pediatr Blood Cancer 2008; 50: 462-467.

7 Lipshultz SE, Adams MJ, Colan SD, Constine LS, Herman EH, Hsu DT, Hudson MM Kremer LC, Landy DC, Miller TL, Oeffinger KC, Rosenthal DN, Sable CA, Sallan SE, Singh GK, Steinberger J, Cochran TR, Wilkinson JD, American Heart Association Congenital Heart Defects Committee of the Council on Cardiovascular Disease in the Young, Council on Basic Cardiovascular Sciences, Council on Cardiovascular and Stroke Nursing, Council on Cardiovascular Radiology and Intervention, Council on Clinical Cardiology, Council on Epidemiology and Prevention and Council on Nutrition, Physical Activity and Metabolism. Long-term cardiovascular toxicity in children, adolescents, and young adults who receive cancer therapy: pathophysiology, course, monitoring, management, prevention, and research directions: a scientific statement from the American Heart Association. Circulation 2013; 128: 1927-1995.

8 Chobanian AV, Bakris GL, Black HR, Cushman WC, Green LA, Izzo JL Jr, Jones DW, Materson BJ, Oparil S, Wright JT Jr, Roccella EJ, National Heart, Lung and Blood Institute Joint National Committee on Prevention, Detection, Evaluation and Treatment of High Blood Pressure; National High Blood Pressure Education Program Coordinating Committee. The Seventh Report of the Joint National Committee on Prevention, Detection, Evaluation, and Treatment of High Blood Pressure: the JNC 7 report. JAMA 2003; 289: 2560-2572.

9 Armstrong GT, Oeffinger KC, Chen Y, Kawashima T, Yasui $Y$, Leisenring W, Stovall M, Chow EJ, Sklar CA, Mulrooney DA, Mertens AC, Border W, Durand JB, Robison LL, Meacham LR. Modifiable risk factors and major cardiac events among adult survivors of childhood cancer. J Clin Oncol 2013; 31: 3673-3680.

10 Oeffinger KC, Mertens AC, Sklar CA, Kawashima T, Hudson MM, Meadows AT, Friedman DL, Marina N, Hobbie W, Kadan-Lottick NS, Schwartz CL, Leisenring W, Robison LL, Childhood Cancer Survivor Study. Chronic health conditions in adult survivors of childhood cancer. N Eng/ J Med 2006; 355: 1572-1582.

11 Oeffinger KC, Buchanan GR, Eshelman DA, Denke MA, Andrews TC, Germak JA, Tomlinson GE, Snell LE, Foster BM. Cardiovascular risk factors in young adult survivors of childhood acute lymphoblastic leukemia. J Pediatr Hematol Oncol 2001; 23: 424-430.

12 Kubota M, Nakata R, Adachi S, Watanabe K, Heike T, Takeshita Y, Shima M. Plasma homocysteine, methionine and S-adenosylhomocysteine levels following high-dose methotrexate treatment in pediatric patients with acute lymphoblastic leukemia or Burkitt lymphoma: association with hepatotoxicity. Leuk Lymphoma 2014; 55: 1591-1595

13 Luzzatto G, Cella G, Messina C, Randi ML, Sbarai A, Zanesco L. Markers of endothelial function in pediatric stem cell transplantation for acute leukemia. Med Pediatr Oncol 2003; 40: 9-12.

14 Endemann DH, Schiffrin EL. Endothelial dysfunction. J Am Soc Nephrol 2004; 15 1983-1992.

15 Schiffrin EL. Role of endothelin-1 in hypertension and vascular disease. Am J Hypertens 2001; 14: 83S-89S

16 Mayyas F, Al-Jarrah M, Ibrahim K, Mfady D, Van Wagoner DR. The significance of circulating endothelin-1 as a predictor of coronary artery disease status and clinical outcomes following coronary artery catheterization. Cardiovasc Pathol 2015; 24: 19-25.

17 Werner N, Kosiol S, Schiegl T, Ahlers P, Walenta K, Link A, Böhm M, Nickenig G. Circulating endothelial progenitor cells and cardiovascular outcomes. N Eng/ J Med 2005; 353: 999-1007.

18 Paczkowska E, Gołąb-Janowska M, Bajer-Czajkowska A, Machalińska A, Ustianowski P, Rybicka M, Kłos P, Dziedziejko V, Safranow K, Nowacki P, Machaliński B. Increased circulating endothelial progenitor cells in patients with haemorrhagic and ischaemic stroke: the role of endothelin-1. J Neurol Sci 2013; 325: 90-99.

19 Balistreri CR, Buffa S, Pisano C, Lio D, Ruvolo G, Mazzesi G. Are endothelial progenitor cells the real solution for cardiovascular diseases? Focus on controversies and perspectives. Biomed Res Int 2015; 2015: 835934.
20 Khan SS, Solomon MA, McCoy JP Jr. Detection of circulating endothelial cells and endothelial progenitor cells by flow cytometry. Cytometry B Clin Cytom 2005; 64: 1-8.

21 Leistner DM, Fischer-Rasokat U, Honold J, Seeger FH, Schächinger V, Lehmann R, Martin H, Burck I, Urbich C, Dimmeler S, Zeiher AM, Assmus B. Transplantation of progenitor cells and regeneration enhancement in acute myocardial infarction (TOPCARE-AMI): final 5-year results suggest long-term safety and efficacy. Clin Res Cardiol 2011; 100: 925-934.

22 Assmus B, Rolf A, Erbs S, Elsässer A, Haberbosch W, Hambrecht R, Tillmanns H, Yu J, Corti R, Mathey DG, Hamm CW, Süselbeck T, Tonn T, Dimmeler S, Dill T, Zeiher AM, Schächinger, V, REPAIR-AMI Investigators. Clinical outcome 2 years after intracoronary administration of bone marrow-derived progenitor cells in acute myocardial infarction. Circ Heart Fail 2010; 3: 89-96.

23 Meacham LR, Chow EJ, Ness KK, Kamdar KY, Chen Y, Yasui Y, Oeffinger KC, Sklar CA, Robison LL, Mertens AC. Cardiovascular risk factors in adult survivors of pediatric cancer-a report from the childhood cancer survivor study. Cancer Epidemiol Biomarkers Prev 2010; 19: 170-181.

24 Esbenshade AJ, Simmons JH, Koyama T, Koehler E, Whitlock JA, Friedman DL. Body mass index and blood pressure changes over the course of treatment of pediatric acute lymphoblastic leukemia. Pediatr Blood Cancer 2011; 56: 372-378.

25 Kourti M, Tragiannidis A, Makedou A, Papageorgiou T, Rousso I, Athanassiadou F. Metabolic syndrome in children and adolescents with acute lymphoblastic leukemia after the completion of chemotherapy. J Pediatr Hematol Oncol 2005; 27: 499-501.

26 Koch VH, Colli A, Saito MI, Furusawa EA, Ignes E, Okay Y, Mion Júnior D. Comparison between casual blood pressure and ambulatory blood pressure monitoring parameters in healthy and hypertensive adolescents. Blood Press Monit 2000; 5: 281-289.

27 Wühl E, Witte K, Soergel M, Mehls O, Schaefer F, German Working Group on Pediatric Hypertension. Distribution of 24-h ambulatory blood pressure in children: normalized reference values and role of body dimensions. J Hypertens 2002; 20: 1995-2007.

28 Dhaun N, Goddard J, Kohan DE, Pollock DM, Schiffrin EL, Webb DJ. Role of endothelin-1 in clinical hypertension: 20 years on. Hypertension 2008; 52: 452-459.

29 Yanagisawa M, Kurihara H, Kimura S, Goto K, Masaki T. A novel peptide vasoconstrictor, endothelin, is produced by vascular endothelium and modulates smooth muscle Ca2+ channels. J Hypertens Supp/ 1988; 6: S188-S191.

30 Kohan DE. Endothelin, hypertension and chronic kidney disease: new insights. Curr Opin Nephrol Hypertens 2010; 19: 134-139.

31 Rautureau Y, Schiffrin EL. Endothelin in hypertension: an update. Curr Opin Nephrol Hypertens 2012; 21: 128-136.

32 Akter S, Jesmin S, Iwashima Y, Hideaki S, Rahman MA, Islam MM, Moroi M, Shimojo N, Yamaguchi N, Miyauchi T, Kawano S, Mizutani T, Kawano Y. Higher circulatory level of endothelin-1 in hypertensive subjects screened through a cross-sectional study of rural Bangladeshi women. Hypertens Res 2015; 38: 208-212.

33 Gehling UM, Ergün S, Schumacher U, Wagener C, Pantel K, Otte M, Schuch G, Schafhausen P, Mende T, Kilic N, Kluge K, Schäfer B, Hossfeld DK, Fiedler W. In vitro differentiation of endothelial cells from AC133-positive progenitor cells. Blood 2000; 95: 3106-3112.

34 Hill JM, Zalos G, Halcox JP, Schenke WH, Waclawiw MA, Quyyumi AA, Finkel T. Circulating endothelial progenitor cells, vascular function, and cardiovascular risk. N Engl J Med 2003; 348: 593-600.

35 Zhen Y, Xiao S, Ren Z, Shen HW, Su H, Tang YB, Zeng H. Increased endothelial progenitor cells and nitric oxide in young prehypertensive women. J Clin Hypertens (Greenwich) 2015; 17: 298-305.

36 Diehl KJ, Weil BR, Westby CM, MacEneaney OJ, Kushner EJ, Greiner JJ, DeSouza CA. Effects of endothelin-1 on endothelial progenitor cell function. Clin Chem Lab Med 2012; 50: 1121-1124.

37 Freixa X, Masotti M, Palomo M, Diaz-Ricart M, Escolar G, Guasch E, Regueiro A, Jiménez $M$, Betriu A, Heras M. Endothelin-1 levels predict endothelial progenitor cell mobilization after acute myocardial infarction. Microvasc Res 2011; 82: 177-181.

38 Yoo SM, Choi SH, Jung MD, Lim SC, Baek SH. Short-term use of telmisartan attenuates oxidation and improves Prdx2 expression more than antioxidant $\beta$-blockers in the cardiovascular systems of spontaneously hypertensive rats. Hypertens Res 2015; 38: $106-115$. 